\title{
Infinitely many solutions for class of Neumann quasilinear elliptic systems
}

Davood Maghsoodi Shoorabi ${ }^{*}$ and Ghasem Alizadeh Afrouzi ${ }^{2}$

* Correspondence: davood.m. s@gmail.com

'Department of Mathematics, Science and Research Branch, Islamic Azad University (IAU), Tehran, Iran

Full list of author information is available at the end of the article

\section{Abstract}

We investigate the existence of infinitely many weak solutions for a class of Neumann quasilinear elliptic systems driven by a $\left(p_{1}, \ldots, p_{n}\right)$-Laplacian operator. The technical approach is fully based on a recent three critical points theorem.

AMS subject classification: 35J65; 34A15.

Keywords: infinitely many solutions, Neumann system, critical point theory, variational methods

\section{Introduction}

The purpose of this article is to establish the existence of infinitely many weak solutions for the following Neumann quasilinear elliptic system

$$
\begin{cases}-\Delta_{p_{i}} u_{i}+a_{i}(x)\left|u_{i}\right|^{p_{i}-2} u=\lambda F_{u_{i}}\left(x, u_{1}, \ldots, u_{n}\right) & \text { in } \Omega, \\ \frac{\partial u_{i}}{\partial v}=0 & \text { on } \partial \Omega\end{cases}
$$

for $i=1, \ldots, n$, where $\Omega \subset \mathbb{R}^{N}(N \geq 1)$ is a non-empty bounded open set with a smooth boundary $\partial \Omega, p_{i}>N$ for $i=1, \ldots, n, \Delta_{p_{i}} u_{i}=\operatorname{div}\left(\left|\nabla u_{i}\right|^{p_{i}-2} \nabla u_{i}\right)$ is the $p_{i}$-Laplacian operator, $a_{i} \in L^{\infty}(\Omega)$ with ess $\inf _{\Omega} a_{i}>0$ for $i=1, \ldots, n, \lambda>0$, and $F: \Omega \times \mathbb{R}^{n} \rightarrow$ $\mathbb{R}$ is a function such that the mapping $\left(t_{1}, t_{2}, \ldots, t_{n}\right) \rightarrow F\left(x, t_{1}, t_{2}, \ldots, t_{n}\right)$ is in $C^{1}$ in $\mathbb{R}^{n}$ for all $x \in \Omega, F_{t_{i}}$ is continuous in $\Omega \times \mathbb{R}^{n}$ for $i=1, \ldots, n$, and $F(x, 0, \ldots, 0)=0$ for all $x$ $\in \Omega$ and $v$ is the outward unit normal to $\partial \Omega$. Here, $F_{t_{i}}$ denotes the partial derivative of $F$ with respect to $t_{i}$.

Precisely, under appropriate hypotheses on the behavior of the nonlinear term $F$ at infinity, the existence of an interval $\Lambda$ such that, for each $\lambda \in \Lambda$, the system (1) admits a sequence of pairwise distinct weak solutions is proved; (see Theorem 3.1). We use a variational argument due to Ricceri which provides certain alternatives in order to find sequences of distinct critical points of parameter-depending functionals. We emphasize that no symmetry assumption is required on the nonlinear term $F$ (thus, the symmetry version of the Mountain Pass theorem cannot be applied). Instead of such a symmetry, we assume a suitable oscillatory behavior at infinity on the function $F$.

We recall that a weak solution of the system (1) is any $u=\left(u_{1}, \ldots, u_{n}\right) \in W^{1, p_{1}}(\Omega) \times \ldots \times W^{1, p_{n}}(\Omega)$, such that

(C) 2012 Shoorabi and Afrouzi; licensee Springer. This is an Open Access article distributed under the terms of the Creative Commons Attribution License (http://creativecommons.org/licenses/by/2.0), which permits unrestricted use, distribution, and reproduction in any medium, provided the original work is properly cited. 


$$
\begin{gathered}
\int_{\Omega} \sum_{i=1}^{n}\left(\left|\nabla u_{i}(x)\right|^{p_{i}-2} \nabla u_{i}(x) \nabla v_{i}(x)+a_{i}(x)\left|u_{i}(x)\right|^{p_{i}-2} u_{i}(x) v_{i}(x)\right) d x \\
-\lambda \int_{\Omega} \sum_{i=1}^{n} F_{u_{i}}\left(x, u_{1}(x), \ldots u_{n}(x)\right) v_{i}(x) d x=0
\end{gathered}
$$

for all $v=\left(v_{1}, \ldots, v_{n}\right) \in W^{1, p_{1}}(\Omega) \times \ldots \times W^{1, p_{n}}(\Omega)$.

For a discussion about the existence of infinitely many solutions for differential equations, using Ricceri's variational principle [1] and its variants $[2,3]$ we refer the reader to the articles [4-16].

For other basic definitions and notations we refer the reader to the articles [17-22]. Here, our motivation comes from the recent article [8]. We point out that strategy of the proof of the main result and Example 3.1 are strictly related to the results and example contained in [8].

\section{Preliminaries}

Our main tool to ensure the existence of infinitely many classical solutions for Dirichlet quasilinear two-point boundary value systems is the celebrated Ricceri's variational principle [[1], Theorem 2.5] that we now recall as follows:

Theorem 2.1. Let $X$ be a reflexive real Banach space, let $\Phi, \Psi: X \rightarrow \mathbb{R}$ be two Gâteaux differentiable functionals such that $\Phi$ is sequentially weakly lower semicontinuous, strongly continuous, and coercive and $\Psi$ is sequentially weakly upper semicontinuous. For every $r>\inf _{X} \Phi$, let us put

$$
\varphi(r):=\inf _{u \in \Phi^{-1}(]-\infty, r[)} \frac{\sup _{v \in \Phi^{-1}(]-\infty, r[)} \Psi(v)-\Psi(u)}{r-\Phi(u)}
$$

and

$$
\gamma:=\liminf _{r \rightarrow+\infty} \varphi(r), \quad \delta:=\liminf _{r \rightarrow\left(\inf _{X} \Phi\right)^{+}} \varphi(r) .
$$

Then, one has

(a) for every $r>\inf _{X} \Phi$ and every $\left.\lambda \in\right] 0, \frac{1}{\varphi(r)}\left[\right.$, the restriction of the functional $I_{\lambda}=$ $\Phi-\lambda \Psi$ to $\Phi^{-1}(]-\infty, r[$ ) admits a global minimum, which is a critical point (local minimum) of $I_{\lambda}$ in $X$.

(b) If $\gamma<+\infty$ then, for each $\lambda \in] 0, \frac{1}{\gamma}[$, the following alternative holds: either

$\left(b_{1}\right) I_{\lambda}$ possesses a global minimum, or

$\left(b_{2}\right)$ there is a sequence $\left\{u_{n}\right\}$ of critical points (local minima) of $I_{\lambda}$ such that $\lim _{n \rightarrow+\infty} \Phi\left(u_{n}\right)=+\infty$

(c) If $\delta<+\infty$ then, for each $\lambda \in] 0, \frac{1}{\delta}[$, the following alternative holds: either 
$\left(c_{1}\right)$ there is a global minimum of $\Phi$ which is a local minimum of $I_{\lambda}$,

or

$\left(c_{2}\right)$ there is a sequence $\left\{u_{n}\right\}$ of pairwise distinct critical points (local minima) of $I_{\lambda}$ that converges weakly to a global minimum of $\Phi$.

We let $X$ be the Cartesian product of $n$ Sobolev spaces $W^{1, p_{1}}(\Omega), W^{1, p_{2}}(\Omega), \ldots$ and $W^{1, p_{n}}(\Omega)$, i.e., $X=\prod_{i=1}^{n} W^{1, p_{i}}(\Omega)$, equipped with the norm

$$
\left\|\left(u_{1}, u_{2}, \ldots, u_{n}\right)\right\|=\sum_{i=1}^{n}\left\|u_{i}\right\|_{p_{i}}
$$

where

$$
\begin{gathered}
\left\|u_{i}\right\|_{p_{i}}=\left(\int_{\Omega}\left|\nabla u_{i}(x)\right|^{p_{i}}+a_{i}(x)\left|u_{i}(x)\right|^{p_{i}} d x\right)^{\frac{1}{p_{i}}}, i=1, \ldots, n . \\
C=\max \left\{\sup _{u_{i} \in W^{1, p_{i}}(\Omega) \backslash\{0\}} \frac{\sup _{x \in \Omega}|u(x)|^{p_{i}}}{\left\|u_{i}\right\|_{p_{i}}^{p_{i}}} ; i=1, \ldots, n\right\} .
\end{gathered}
$$

Since $p_{i}>N$ for $1 \leq i \leq n$, one has $C<+\infty$. In addition, if $\Omega$ is convex, it is known [23] that

$$
\sup _{u_{i} \in W^{1, p_{i}(\Omega) \backslash\{0\}}} \frac{\sup _{x \in \Omega}\left|u_{i}(x)\right|}{\left\|u_{i}\right\|_{p_{i}}} \leq 2 \frac{p_{i}-1}{p_{i}} \max \left\{\left(\frac{1}{\left\|a_{i}\right\|_{1}}\right)^{\frac{1}{p_{i}}} ; \frac{\operatorname{diam}(\Omega)}{N^{\frac{1}{p_{i}}}}\left(\frac{p_{i}-1}{p_{i}-N} m(\Omega)\right)^{\frac{p_{i}-1}{p_{i}}} \frac{\left\|a_{i}\right\|_{\infty}}{\left\|a_{i}\right\|_{1}}\right\}
$$

for $1 \leq i \leq n$, where ||$\cdot\left\|_{1}=\int_{\Omega}|\cdot(x)| d x,\right\| \cdot \|_{\infty}=\sup _{x \in \Omega}|\cdot(x)|$ and $m(\Omega)$ is the Lebesgue measure of the set $\Omega$, and equality occurs when $\Omega$ is a ball.

In the sequel, let $\underline{p}=\min \left\{p_{i} ; 1 \leq i \leq n\right\}$.

For all $\gamma>0$ we define

$$
K(\gamma)=\left\{\left(t_{1}, \ldots, t_{n}\right) \in \mathbb{R}^{n}: \sum_{i=1}^{n}\left|t_{i}\right| \leq \gamma\right\} .
$$

\section{Main results}

We state our main result as follows:

Theorem 3.1. Assume that

(A1)

$$
\begin{gathered}
\liminf _{\xi \rightarrow+\infty} \frac{\int_{\Omega} \sup _{\left(t_{1}, \ldots, t_{n}\right) \in K(\xi)} F\left(x, t_{1}, \ldots, t_{n}\right) d x}{\xi^{p}} \\
<\left(\sum_{i=1}^{n}\left(p_{i} C\right)^{\frac{1}{p_{i}}}\right)^{p} \limsup _{\substack{\left(t_{1}, \ldots, t_{n}\right) \rightarrow \infty \\
\left(t_{1}, \ldots, t_{n}\right) \in \mathbb{R}_{+}^{n}}} \frac{\int_{\Omega} F\left(x, t_{1}, \ldots, t_{n}\right) d x}{\sum_{i=1}^{n} \frac{\left\|a_{i}\right\|_{1}\left|t_{i}\right|_{i}}{p_{i}}}
\end{gathered}
$$

where $K(\xi)=\left\{\left(t_{1}, \ldots, t_{n}\right)\left|\sum_{i=1}^{n}\right| t_{i} \mid \leq \xi\right\} \quad$ (see (3)). 
Then, for each

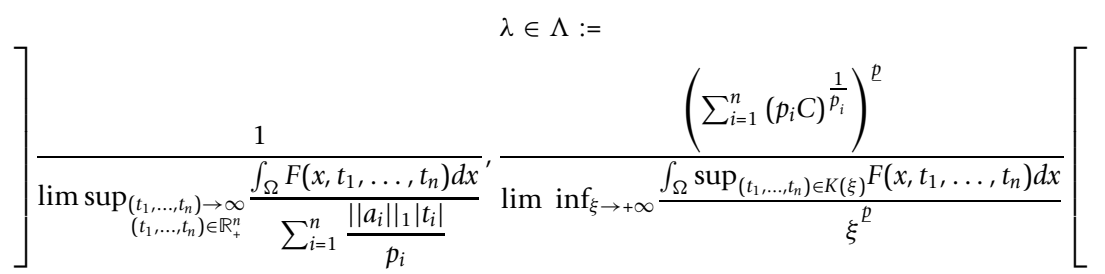

the system (1) has an unbounded sequence of weak solutions in $X$.

Proof. Define the functionals $\Phi, \Psi: X \rightarrow \mathbb{R}$ for each $u=\left(u_{1}, \ldots, u_{n}\right) \in X$, as follows

$$
\Phi(u)=\sum_{i=1}^{n} \frac{\left\|u_{i}\right\|_{p_{i}}^{p_{i}}}{p_{i}}
$$

and

$$
\Psi(u)=\int_{\Omega} F\left(x, u_{1}(x), \ldots, u_{n}(x)\right) d x .
$$

It is well known that $\Psi$ is a Gâteaux differentiable functional and sequentially weakly lower semicontinuous whose Gâteaux derivative at the point $u \in X$ is the functional $\Psi^{\prime}(u) \in X^{*}$, given by

$$
\Psi^{\prime}(u)(v)=\int_{\Omega} \sum_{i=1}^{n} F_{u_{i}}\left(x, u_{1}(x), \ldots, u_{n}(x)\right) v_{i}(x) d x
$$

for every $v=\left(v_{1}, \ldots, v_{n}\right) \in X$, and $\Psi^{\prime}: X \rightarrow X^{*}$ is a compact operator. Moreover, $\Phi$ is a sequentially weakly lower semicontinuous and Gâteaux differentiable functional whose Gâteaux derivative at the point $u \in X$ is the functional $\Phi^{\prime}(u) \in X^{*}$, given by

$$
\Phi^{\prime}\left(u_{1}, \ldots, u_{n}\right)\left(v_{1}, \ldots, v_{n}\right) \int_{\Omega} \sum_{i=1}^{n}\left(\left|\nabla u_{i}(x)\right|^{p_{i}-2} \nabla u_{i}(x) \nabla v_{i}(x)+a_{i}(x)\left|u_{i}(x)\right|^{p_{i}-2} u_{i}(x) v_{i}(x)\right) d x
$$

for every $v=\left(v_{1}, \ldots, v_{n}\right) \in X$. Furthermore, $\left(\Phi^{\prime}\right)^{-1}: X^{*} \rightarrow X$ exists and is continuous.

Put $I_{\lambda}:=\Phi-\lambda \Psi$. Clearly, the weak solutions of the system (1) are exactly the solutions of the equation $I_{\lambda}^{\prime}\left(u_{1}, \ldots, u_{n}\right)=0$. Now, we want to show that

$$
\gamma<+\infty \text {. }
$$

Let $\left\{\xi_{m}\right\}$ be a real sequence such that $\xi_{m} \rightarrow+\infty$ as $m \rightarrow \infty$ and

$$
\begin{aligned}
& \lim _{m \rightarrow \infty} \frac{\int_{\Omega} \sup _{\left(t_{1}, \ldots, t_{n}\right) \in K\left(\xi_{m}\right)} F\left(x, t_{1}, \ldots, t_{n}\right) d x}{\xi_{m}^{p}} \\
& =\liminf _{\xi \rightarrow+\infty} \frac{\int_{\Omega} \sup _{\left(t_{1}, \ldots, t_{n}\right) \in K(\xi)} F\left(x, t_{1}, \ldots, t_{n}\right) d x}{\xi^{p}} . \\
& \text { Put } \left.r_{m}=\frac{\xi_{m}^{p}}{\left(\sum_{i=1}^{n}\left(p_{i} C\right)\right.} \frac{1}{p_{i}}\right)^{p} \text { for all } m \in \mathbb{N} \text {. Since } \\
& \sup _{x \in \Omega}\left|u_{i}(x)\right|^{p_{i}} \leq C\left\|u_{i}\right\|_{p_{i}}^{p_{i}}
\end{aligned}
$$


for each $u_{i} \in W^{1, p_{i}}(\Omega)$ for $1 \leq i \leq n$, we have

$$
\sup _{x \in \Omega} \sum_{i=1}^{n} \frac{\left|u_{i}(x)\right|^{p_{i}}}{p_{i}} \leq C \sum_{i=1}^{n} \frac{\left\|u_{i}\right\|_{p_{i}}^{p_{i}}}{p_{i}}
$$

for each $u=\left(u_{1}, u_{2}, \ldots, u_{n}\right) \in X$. This, for each $r>0$, together with (4), ensures that

$$
\left.\left.\Phi^{-1}(]-\infty, r\right]\right) \subseteq\left\{u \in X ; \sup \sum_{i=1}^{n} \frac{\left|u_{i}(x)\right|^{p_{i}}}{p_{i}} \leq C r \text { for each } x \in \Omega\right\} .
$$

Hence, an easy computation shows that $\sum_{i=1}^{n}\left|u_{i}\right| \leq \xi_{m}$ whenever $u=\left(u_{1}, \ldots, u_{n}\right) \in$ $\left.\left.\Phi^{-1}(]-\infty, r_{m}\right]\right)$. Hence, one has

$$
\begin{aligned}
& \varphi\left(r_{m}\right)=\inf _{u \in \Phi^{-1}(]-\infty, r_{m}[)} \frac{\left(\sup _{v \in \Phi^{-1}(]-\infty, r_{m}[)} \Psi(v)\right)-\Phi(u)}{r_{m}-\Phi(u)} \\
& \leq \frac{\sup _{\left.v \in \Phi^{-1}(]-\infty, r_{m}\right]} \Psi(v)}{r_{m}} \\
& \leq \frac{\int_{\Omega} \sup _{\left(t_{1}, \ldots, t_{n}\right) \in K\left(\xi_{m}\right)} F\left(x, t_{1}, \ldots, t_{n}\right) d x}{p} . \\
& \frac{\xi_{m}}{\left(\sum_{i=1}^{n}\left(p_{i} C\right)^{\frac{1}{p_{i}}}\right)^{p}}
\end{aligned}
$$

Therefore, since from Assumption (A1) one has

$$
\liminf _{\xi \rightarrow+\infty} \frac{\int_{\Omega} \sup _{\left(t_{1}, \ldots, t_{n}\right) \in K(\xi)} F\left(x, t_{1}, \ldots, t_{n}\right) d x}{\xi^{p}}<\infty,
$$

we deduce

$$
\begin{gathered}
\gamma \leq \liminf _{m \rightarrow+\infty} \varphi\left(r_{m}\right) \\
\leq\left(\sum_{i=1}^{n}\left(p_{i} C\right) \frac{1}{p_{i}}\right)^{p} \liminf _{\xi \rightarrow+\infty} \frac{\int_{\Omega} \sup _{\left(t_{1}, \ldots, t_{n}\right) \in K(\xi)} F\left(x, t_{1}, \ldots, t_{n}\right) d x}{\xi^{p}}<+\infty .
\end{gathered}
$$

Assumption (A1) along with (5), implies

$$
\Lambda \subseteq] 0, \frac{1}{\gamma}[\text {. }
$$

Fix $\lambda \in \Lambda$. The inequality (5) concludes that the condition (b) of Theorem 2.1 can be applied and either $I_{\lambda}$ has a global minimum or there exists a sequence $\left\{u_{m}\right\}$ where $u_{m}=$ $\left(u_{1 m}, \ldots, u_{n m}\right)$ of weak solutions of the system (1) such that $\lim _{m \rightarrow \infty}\left\|\left(u_{1 m}, \ldots, u_{n m}\right)\right\|=+\infty$.

Now fix $\lambda \in \Lambda$ and let us verify that the functional $I_{\lambda}$ is unbounded from below. Arguing as in [8], consider $n$ positive real sequences $\left\{d_{i, m}\right\}_{i=1}^{n}$ such that $\sqrt{\sum_{i=1}^{n} d_{i, m}^{2}} \rightarrow+\infty$ as $m \rightarrow \infty$

and

$$
\lim _{m \rightarrow+\infty} \frac{\int_{\Omega} F\left(x, d_{1, m}, \ldots, d_{n, m}\right) d x}{\sum_{i=1}^{n} \frac{d_{i, m}^{p_{i}}}{p_{i}}}=\limsup _{\substack{\left(t_{1}, \ldots, t_{n}\right) \rightarrow \infty \\\left(t_{1}, \ldots, t_{n}\right) \in \mathbb{R}_{+}^{n}}} \frac{\int_{\Omega} F\left(x, t_{1}, \ldots, t_{n}\right) d x}{\sum_{i=1}^{n} \frac{\left\|a_{i}\right\|_{1}\left|t_{i}\right|_{i}^{p_{i}}}{p_{i}}} .
$$


For all $m \in \mathbb{N}$ define $w_{m}(x)=\left(d_{1, m}, \ldots, d_{n, m}\right)$. For any fixed $m \in \mathbb{N}, w_{m} \in X$ and, in particular, one has

$$
\Phi\left(w_{m}\right)=\sum_{i=1}^{n} \frac{d_{i, m}^{p_{i}}\left\|a_{i}\right\|_{1}}{p_{i}} .
$$

Then, for all $m \in \mathbb{N}$,

$$
I_{\lambda}\left(w_{m}\right)=\Phi\left(w_{m}\right)-\lambda \Psi\left(w_{m}\right)=\sum_{i=1}^{n} \frac{d_{i, m}^{p_{i}}\left\|a_{i}\right\|_{1}}{p_{i}}-\lambda \int_{\Omega} F\left(x, d_{1, m}, \ldots, d_{n, m}\right) d x .
$$

Now, if

$$
\limsup _{\substack{\left(t_{1}, \ldots, n_{n}\right) \rightarrow \infty \\\left(t_{1}, \ldots, t_{n}\right) \in \mathbb{R}_{+}^{n}}} \frac{\int_{\Omega} F\left(x, t_{1}, \ldots, t_{n}\right) d x}{\sum_{i=1}^{n} \frac{\left\|a_{i}\right\|_{1}\left|t_{i}\right|_{i}}{p_{i}}}<\infty
$$

we fix $\epsilon \in] \frac{1}{\lambda \lim \sup _{\left(t_{1}, \ldots, t_{n}\right) \rightarrow \infty} \frac{\int_{\Omega} F\left(x, t_{1}, \ldots, t_{n}\right) d x}{\left(t_{1}, \ldots, t_{n}\right) \in \mathbb{R}_{+}^{n}} \sum_{i=1}^{n} \frac{\left\|a_{i}\right\|_{1}\left|t_{i}\right|_{i}}{p_{i}}}, 1$. From (6) there exists $\tau_{\varepsilon}$ such that

$$
>\epsilon \limsup _{\substack{\left(t_{1}, \ldots, t_{n}\right) \rightarrow \infty \\\left(t_{1}, \ldots, t_{n}\right) \in \mathbb{R}_{+}^{n}}} \frac{\int_{\Omega} F\left(x, t_{1}, \ldots, t_{n}\right) d x}{\sum_{i=1}^{n} \frac{\left\|a_{i}\right\|_{1}\left|t_{i}\right|^{p_{i}}}{p_{i}}}\left(\sum_{i=1}^{n} \frac{d_{i, m}^{p_{i}}\left\|a_{i}\right\|_{1}}{p_{i}}\right) \quad \forall m>\tau_{\epsilon},
$$

therefore

$$
I_{\lambda}\left(w_{m}\right) \leq\left(1-\lambda \epsilon \limsup _{\substack{\left(t_{1}, \ldots, n_{n}\right) \rightarrow \infty \\\left(t_{1}, \ldots, h_{n}\right) \in \mathbb{R}_{+}^{n}}} \frac{\int_{\Omega} F\left(x, t_{1}, \ldots, t_{n}\right) d x}{\sum_{i=1}^{n} \frac{\left\|a_{i}\right\|_{1}\left|t_{i}\right|_{i}}{p_{i}}}\right) \sum_{i=1}^{n} \frac{d_{i, m}^{p_{i}}\left\|a_{i}\right\|_{1}}{p_{i}} \forall m>\tau_{\epsilon},
$$

and by the choice of $\varepsilon$, one has

$$
\lim _{m \rightarrow+\infty}\left[\Phi\left(w_{m}\right)-\lambda \Psi\left(w_{m}\right)\right]=-\infty .
$$

If

$$
\limsup _{\xi \rightarrow+\infty} \frac{\int_{\Omega} F\left(x, t_{1}, \ldots, t_{n}\right) d x}{\sum_{i=1}^{n} \frac{\left\|a_{i}\right\|_{1} \mid t_{i} p_{i}}{p_{i}}}=\infty
$$

let us consider $K>\frac{1}{\lambda}$. From (6) there exists $\tau_{K}$ such that

$$
\int_{\Omega} F\left(x, d_{1, m}, \ldots, d_{n, m}\right) d x>K \sum_{i=1}^{n} \frac{d_{i, m}^{p_{i}}\left\|a_{i}\right\|_{1}}{p_{i}} \forall m>\tau_{K}
$$

therefore

$$
I_{\lambda}\left(w_{m}\right) \leq(1-\lambda K) \sum_{i=1}^{n} \frac{d_{i, m}^{p_{i}}\left\|a_{i}\right\|_{1}}{p_{i}} \forall m>\tau_{K},
$$


and by the choice of $K$, one has

$$
\lim _{m \rightarrow+\infty}\left[\Phi\left(w_{m}\right)-\lambda \Psi\left(w_{m}\right)\right]=-\infty .
$$

Hence, our claim is proved. Since all assumptions of Theorem 2.1 are satisfied, the functional $I_{\lambda}$ admits a sequence $\left\{u_{m}=\left(u_{1 m}, \ldots, u_{n m}\right)\right\} \subset X$ of critical points such that

$$
\lim _{m \rightarrow \infty}\left\|\left(u_{1 m}, \ldots, u_{n m}\right)\right\|=+\infty,
$$

and we have the conclusion.

Here, we give a consequence of Theorem 3.1.

Corollary 3.2. Assume that

(A2) $\liminf \inf _{\xi \rightarrow+\infty} \frac{\int_{\Omega} \sup _{\left(t_{1}, \ldots, t_{n}\right) \in K(\xi)} F\left(x, t_{1}, \ldots, t_{n}\right) d x}{\xi^{p}}<\left(\sum_{i=1}^{n}\left(p_{i} C\right)^{\frac{1}{p_{i}}}\right)^{p}$;

(A3) $\lim \sup _{\substack{\left(t_{1}, \ldots, t_{n}\right) \rightarrow \infty \\\left(t_{1}, \ldots, t_{n}\right) \in \mathbb{R}_{+}^{n}}} \frac{\int_{\Omega} F\left(x, t_{1}, \ldots, t_{n}\right) d x}{\sum_{i=1}^{n} \frac{\left\|a_{i}\right\|_{1} l_{i} t_{i} p_{i}}{\rho_{i}}}>1$.

Then, the system

$$
\begin{cases}-\Delta_{p_{i}} u_{i}+a_{i}(x)\left|u_{i}\right|^{p_{i}-2} u=F_{u_{i}}\left(x, u_{1}, \ldots, u_{n}\right) & \text { in } \Omega \\ \frac{\partial u_{i}}{\partial v}=0 & \text { on } \partial \Omega\end{cases}
$$

for $1 \leq i \leq n$, has an unbounded sequence of classical solutions in $X$.

Now, we want to present the analogous version of the main result (Theorem 3.1) in the autonomous case.

Theorem 3.3. Assume that

(A4)

$$
\begin{aligned}
& \liminf _{\xi \rightarrow+\infty} \frac{\sup _{\left(t_{1}, \ldots, t_{n}\right) \in K(\xi)} F\left(t_{1}, \ldots, t_{n}\right)}{\xi^{p}} \\
&<\left(\sum_{i=1}^{n}\left(p_{i} C\right)^{p} \frac{1}{p_{i}}\right)^{p} \limsup _{\substack{\left(t_{1}, \ldots, t_{n}\right) \rightarrow \infty \\
\left(t_{1}, \ldots, t_{n}\right) \in \mathbb{R}_{+}^{n}}} \frac{F\left(t_{1}, \ldots, t_{n}\right)}{\sum_{i=1}^{n} \frac{\left\|a_{i}\right\|_{1} \mid t_{i} p_{i}}{p_{i}}}
\end{aligned}
$$

where $K(\xi)=\left\{\left(t_{1}, \ldots, t_{n}\right)\left|\sum_{i=1}^{n}\right| t_{i} \mid \leq \xi\right\}$ (see (3)).

Then, for each

$$
\begin{aligned}
& \lambda \in \Lambda:= \\
& ] \frac{1}{\frac{F\left(t_{1}, \ldots, t_{n}\right)}{\lim \sup \left(t_{1}, \ldots, t_{n}\right) \rightarrow \infty}\left(\sum_{i=1}^{n} \frac{\left\|a_{i}\right\|_{1}\left|t_{i}\right|}{\left.p_{i}, \ldots, t_{n}\right) \in \mathbb{R}_{+}^{n}}\right.}, \frac{\left(\sum_{i=1}^{n}\left(p_{i} C\right)^{\frac{1}{p_{i}}}\right)^{p}}{\lim \inf _{\xi \rightarrow+\infty} \frac{\sup _{\left(t_{1}, \ldots, t_{n}\right) \in K(\xi)} F\left(t_{1}, \ldots, t_{n}\right)}{\xi^{p}}}[
\end{aligned}
$$


the system

$$
\left\{\begin{array}{lr}
-\Delta_{p_{i}} u_{i}+a_{i}(x)\left|u_{i}\right|^{p_{i}-2} u=\lambda F_{u_{i}}\left(u_{1}, \ldots, u_{n}\right) & \text { in } \Omega, \\
\frac{\partial u_{i}}{\partial v}=0 & \text { on } \partial \Omega
\end{array}\right.
$$

has an unbounded sequence of weak solutions in $X$.

Proof. Set $F\left(x, u_{1}, \ldots, u_{n}\right)=F\left(u_{1}, \ldots, u_{n}\right)$ for all $x \in \Omega$ and $\left(u_{1}, \ldots, u_{n}\right) \in \mathbb{R}^{n}$. The conclusion follows from Theorem 3.1.

Remark 3.1. We observe in Theorem 3.1 we can replace $\xi \rightarrow+\infty$ and $\left(t_{1}, \ldots, t_{n}\right) \rightarrow$ $(+\infty, \ldots,+\infty)$ with $\xi \rightarrow 0^{+}\left(t_{1}, \ldots, t_{n}\right) \rightarrow\left(0^{+}, \ldots, 0^{+}\right)$, respectively, that by the same way as in the proof of Theorem 3.1 but using conclusion (c) of Theorem 2.1 instead of (b), the system (1) has a sequence of weak solutions, which strongly converges to 0 in $X$.

Finally, we give an example to illustrate the result.

Example 3.1. Let $\Omega \subset \mathbb{R}^{2}$ be a non-empty bounded open set with a smooth boundary $9 \Omega$ and consider the increasing sequence of positive real numbers given by

$$
a_{n}:=2, \quad a_{n+1}:=n !\left(a_{n}\right)^{\frac{5}{4}}+2
$$

for every $n \geq 1$. Define the function

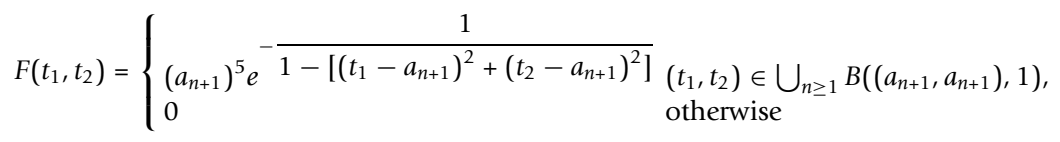

where $\left.B\left(\left(a_{n+1}, a_{n+1}\right), 1\right)\right)$ be the open unit ball of center $\left(a_{n+1}, a_{n+1}\right)$. We observe that the function $F$ is non-negative, $F(0,0)=0$, and $F \in C^{1}\left(\mathbb{R}^{2}\right)$. We will denote by $f$ and $g$, respectively, the partial derivative of $F$ respect to $t_{1}$ and $t_{2}$. For every $n \in \mathbb{N}$, the restriction $F$ on $B\left(\left(a_{n+1}, a_{n+1}\right), 1\right)$ attains its maximum in $\left(a_{n+1}, a_{n+1}\right)$ and $F\left(a_{n+1}, a_{n+1}\right)$ $=\left(a_{n+1}\right)^{5}$,

then

$$
\limsup _{n \rightarrow+\infty} \frac{F\left(a_{n+1}, a_{n+1}\right)}{\frac{a_{n+1}^{3}}{3}+\frac{a_{n+1}^{4}}{4}}=+\infty
$$

So

$$
\limsup _{\left(t_{1}, t_{2}\right) \rightarrow(+\infty,+\infty)} \frac{F\left(t_{1}, t_{2}\right)}{\frac{\left|t_{1}\right|^{3}}{3}+\frac{\left|t_{2}\right|^{4}}{4}}=+\infty
$$

On the other by setting $y_{n}=a_{n+1}-1$ for every $n \in \mathbb{N}$, one has

$$
\sup _{\left(t_{1}, t_{2}\right) \in K\left(y_{n}\right)} F\left(t_{1}, t_{2}\right)=a_{n}^{5} \quad \forall n \in \mathbb{N}
$$

Then

$$
\lim _{n \rightarrow \infty} \frac{\sup _{\left(t_{1}, t_{2}\right) \in K\left(y_{n}\right)} F\left(t_{1}, t_{2}\right)}{\left(a_{n+1}-1\right)^{3}}=0,
$$


and hence

$$
\liminf _{\xi \rightarrow \infty} \frac{\sup _{\left(t_{1}, t_{2}\right) \in K(\xi)} F\left(t_{1}, t_{2}\right)}{\xi^{3}}=0 .
$$

Finally

$$
\begin{gathered}
0=\liminf _{\xi \rightarrow+\infty} \frac{\sup _{\left(t_{1}, t_{2}\right) \in K(\xi)} F\left(t_{1}, t_{2}\right)}{\xi^{3}} \\
<\left((3 C)^{\frac{1}{3}}+(4 C)^{\frac{1}{4}}\right)^{3} \limsup _{\left(t_{1}, t_{2}\right) \rightarrow(+\infty,+\infty)_{\left(t_{1}, t_{2}\right) \in \mathbb{R}_{+}^{R}}} \frac{F\left(t_{1}, t_{2}\right)}{\frac{\left|t_{1}\right|^{3}}{3}+\frac{\left|t_{2}\right|^{4}}{4}}=+\infty .
\end{gathered}
$$

So, since all assumptions of Theorem 3.3 is applicable to the system

$$
\begin{cases}-\Delta_{3} u+|u| u=\lambda f(u, v) & \text { in } \Omega, \\ -\Delta_{4} v+|v|^{2} g=\lambda g(u, v) & \text { in } \Omega, \\ \frac{\partial u}{\partial v}=\frac{\partial v}{\partial v}=0 & \text { on } \Omega\end{cases}
$$

for every $\lambda \in[0,+\infty[$.

\section{Author details}

${ }^{1}$ Department of Mathematics, Science and Research Branch, Islamic Azad University (IAU), Tehran, Iran ${ }^{2}$ Department of Mathematics, Faculty of Basic Sciences, University of Mazandaran, 47416-1467 Babolsar, Iran

\section{Authors' contributions}

DMS has presented the main purpose of the article and has used GAA contribution due to reaching to conclusions. All authors read and approved the final manuscript.

\section{Competing interests}

The authors declare that they have no competing interests.

Received: 30 January 2012 Accepted: 6 May 2012 Published: 6 May 2012

\section{References}

1. Ricceri, B: A general variational principle and some of its applications. J Comput Appl Math. 113, 401-410 (2000). doi:10.1016/S0377-0427(99)00269-1

2. Bonanno, G, Molica Bisci, G: Infinitely many solutions for a boundary value problem with discontinuous nonlinearities. Bound Value Probl. 2009, 1-20 (2009)

3. Marano, S, Motreanu, D: Infinitely many critical points of non-differentiable functions and applications to the Neumanntype problem involving the p-Laplacian. J Diff Equ. 182, 108-120 (2002). doi:10.1006/jdeq.2001.4092

4. Bonanno, G, D'Aguì, G: On the Neumann problem for elliptic equations involving the $p$-Laplacian. J Math Anal Appl. 358, 223-228 (2009). doi:10.1016/j.jmaa.2009.04.055

5. Bonanno, G, Di Bella, B: Infinitely many solutions for a fourth-order elastic beam equation. Nonlinear Diff Equ Appl NoDEA. 18, 357-368 (2011). doi:10.1007/s00030-011-0099-0

6. Bonanno, G, Molica Bisci, G: A remark on perturbed elliptic Neumann problems. Studia Univ "Babeș-Bolyai", Mathematica. LV(4) (2010)

7. Bonanno, G, Molica Bisci, G: Infinitely many solutions for a Dirichlet problem involving the p-Laplacian. Proc Royal Soc Edinburgh. 140A, 737-752 (2010)

8. Bonanno, G, Molica Bisci, G, O'Regan, D: Infinitely many weak solutions for a class of quasilinear elliptic systems. Math Comput Model. 52, 152-160 (2010). doi:10.1016/j.mcm.2010.02.004

9. Bonanno, G, Molica Bisci, G, Rădulescu, V: Infinitely many solutions for a class of nonlinear eigenvalue problems in Orlicz-Sobolev spaces. C R Acad Sci Paris, Ser I. 349, 263-268 (2011). doi:10.1016/j.crma.2011.02.009

10. Candito, P: Infinitely many solutions to the Neumann problem for elliptic equations involving the $p$-Laplacian and with discontinuous nonlinearities. Proc Edin Math Soc. 45, 397-409 (2002)

11. Candito, P, Livrea, R: Infinitely many solutions for a nonlinear Navier boundary value problem involving the $p$ biharmonic. Studia Univ "Babeș-Bolyai", Mathematica. LV(4) (2010)

12. Dai, G: Infinitely many solutions for a Neumann-type differential inclusion problem involving the $p(x)$-Laplacian. Nonlinear Anal. 70, 2297-2305 (2009). doi:10.1016/j.na.2008.03.009

13. Fan, X, Ji, C: Existence of infinitely many solutions for a Neumann problem involving the $\mathrm{p}(\mathrm{x})$-Laplacian. J Math Anal Appl. 334, 248-260 (2007). doi:10.1016/j.jmaa.2006.12.055

14. Kristály, A: Infinitely many solutions for a differential inclusion problem in $\bigotimes^{N}$. J Diff Equ. 220, 511-530 (2006). doi:10.1016/j.jde.2005.02.007 
15. Li, C: The existence of infinitely many solutions of a class of nonlinear elliptic equations with a Neumann boundary conditions for both resonance and oscillation problems. Nonlinear Anal. 54, 431-443 (2003). doi:10.1016/50362-546X(03) 00100-7

16. Ricceri, B: Infinitely many solutions of the Neumann problem for elliptic equations involving the $p$-Laplacian. Bull Lond Math Soc. 33(3):331-340 (2001). doi:10.1017/50024609301008001

17. Afrouzi, GA, Heidarkhani, $\mathrm{S}$ : Existence of three solutions for a class of Dirichlet quasi-linear elliptic systems involving the $\left(p_{1}, \ldots, p_{n}\right)$-Laplacian. Nonlinear Anal. 70, 135-143 (2009). doi:10.1016/j.na.2007.11.038

18. Afrouzi, GA, Heidarkhani, S, O'Regan, D: Three solutions to a class of Neumann doubly eigenvalue elliptic systems driven by a $\left(p_{1}, \ldots . . p_{n}\right)$-Laplacian. Bull Korean Math Soc. 47(6):1235-1250 (2010). doi:10.4134/BKMS.2010.47.6.1235

19. Bonanno, G, Heidarkhani, S, O'Regan, D: Multiple solutions for a class of Dirichlet quasilinear elliptic systems driven by a (p, q)-Laplacian operator. Dyn Syst Appl. 20, 89-100 (2011)

20. Heidarkhani, S, Tian, Y: Multiplicity results for a class of gradient systems depending on two parameters. Nonlinear Anal. 73, 547-554 (2010). doi:10.1016/.jna.2010.03.051

21. Heidarkhani, S, Tian, Y: Three solutions for a class of gradient Kirchhoff-type systems depending on two parameters. Dyn Syst Appl. 20, 551-562 (2011)

22. Zeidler, E: Nonlinear Functional Analysis and its Applications. Springer, New Yorkll (1985)

23. Bonanno, G, Candito, P: Three solutions to a Neumann problem for elliptic equations involving the $p$-Laplacian. Arch Math (Basel). 80, 424-429 (2003)

doi:10.1186/1687-2770-2012-54

Cite this article as: Shoorabi and Afrouzi: Infinitely many solutions for class of Neumann quasilinear elliptic systems. Boundary Value Problems 2012 2012:54.

\section{Submit your manuscript to a SpringerOpen ${ }^{\odot}$} journal and benefit from:

- Convenient online submission

- Rigorous peer review

- Immediate publication on acceptance

- Open access: articles freely available online

- High visibility within the field

- Retaining the copyright to your article

Submit your next manuscript at $\boldsymbol{s p r i n g e r o p e n . c o m ~}$ 